\title{
RELAÇÕES ENTRE ATRIBUTOS DO SOLO E ATIVIDADE DE FORMIGAS EM RESTINGAS ${ }^{(1)}$
}

\author{
João Bosco Vasconcellos Gomes ${ }^{(2)}$, Antonio Carlos Barreto ${ }^{(3)}$, Miguel \\ Michereff Filho $^{(4)}$, Wiviane Carlos Lima Vidal ${ }^{(5)}$, Jefferson Luis da Silva \\ Costa $^{(6)}$, Ary Teixeira de Oliveira-Filho( ${ }^{(7)} \&$ Nilton Curi ${ }^{(8)}$
}

\begin{abstract}
RESUMO
Em solos de restinga de constituição areno-quartzosa aumenta a influência da fração orgânica e da atividade biológica em funções-chave dos solos, como a capacidade de reciclar e armazenar nutrientes. A análise de atributos do solo e da fauna edáfica em sítios sob diferentes coberturas vegetais é importante para entender o comportamento desses ambientes. Neste estudo, avaliaram-se atributos químicos, físicos e microbiológicos do solo e suas relações com a população de formigas de sítios de restinga sob diferentes coberturas vegetais no Estado de Sergipe. Foram coletadas amostras em seis coberturas vegetais (três sítios por cobertura), sendo quatro na área Caju (mata, capim-gengibre, coqueiral e capoeira) e duas na área Pirambu (mata de topo de duna e mata de sopé de duna). As análises químicas foram feitas em amostras coletadas nas camadas de 0-5 e 5-20 cm, e a atividade microbiana, avaliada por meio da hidrólise do diacetato de fluoresceína, foi determinada em amostras coletadas a 0-10 cm. A massa de fragmentos orgânicos foi avaliada em diferentes profundidades. Na avaliação das comunidades de formigas foram consideradas aquelas com atividade na superfície do solo. $\mathrm{Na}$ comparação entre os sítios foi utilizada a análise de componentes principais. Os atributos de compartimentos orgânicos (C orgânico, C orgânico dissolvido e fragmentos orgânicos) foram muito sensíveis à modificação da cobertura vegetal nos sítios do Caju, isolando os sítios sob mata dos alterados e os sítios sob capim-
\end{abstract}

\footnotetext{
(1) Projeto executado com recursos da FAPITEC-SE. Recebido para publicação em março de 2009 e aprovado em novembro de 2009.

(2) Pesquisador da Embrapa Florestas. Estrada da Ribeira, km 111, CEP 83411-000 Colombo (PR). E-mail: jbvgomes@cnpf.embrapa.br

(3) Pesquisador da Embrapa Tabuleiros Costeiros. Av. Beira-Mar 3250, CEP 49025-040 Aracaju (SE). E-mail: barreto@cpatc.embrapa.br

(4) Pesquisador da Embrapa Hortaliças. E-mail: miguel@cnph.embrapa.br

(5) Pesquisadora da Embrapa Informação Tecnológica. E-mail: wyviane@sct.embrapa.br

(6) Pesquisador da Embrapa Departamento de Pesquisa e Desenvolvimento. E-mail: jefferson.costa@embrapa.br

(7) Professor do Departamento de Botânica, ICP, Universidade Federal de Minas Gerais - UFMG. Caixa Postal 486, CEP 31270 901 Belo Horizonte (MG). E-mail: ary@icb.ufmg.br

(8) Professor do Departamento de Ciência do Solo, Universidade Federal de Lavras - UFLA. Caixa Postal 37, CEP 37200-000 Lavras (MG). E-mail: niltcuri@ufla.br
} 
gengibre daqueles sob capoeira e coqueiral. Atributos da solução do solo influenciáveis pelo spray marinho (condutividade elétrica e concentração de $K$, $\mathrm{Na}$ e Mg) isolaram os sítios de Pirambu dos sítios do Caju. Os grupos de formiga mostraram elevado nível de especialização. A análise de correspondência canônica apontou baixa percentagem da variância da distribuição desses grupos e isolou os sítios de mata dos outros usos, indicando que existem outros atributos a serem considerados na distribuição.

Termos de indexação: Espodossolos, Neossolos Quartzarênicos, fauna do solo, análises multivariadas.

\title{
SUMMARY: RELATIONSHIP AMONG SOIL ATTRIBUTES AND ANT ACTIVITY IN RESTINGA SOILS
}

\begin{abstract}
In restinga soils with sand-quartzous constitution the influence of the organic fraction and biological activity on soil key functions is increased, e.g., the capacity of recycling and storing nutrients. The analysis of soil attributes and edaphic fauna at sites under different vegetation cover types is important to understand the behavior of these environments. In this study, chemical, physical and microbiological soil attributes of restinga sites and their relationships with ant populations under different vegetation types in the state of Sergipe were evaluated. Samples of six vegetation types (three sites per cover) were collected, four of which in the area of Caju (forest, ginger-grass, coconut palm plantation and brushwood) and two in the area of Pirambu (dune plateau forest and dune footslope forest). Chemical attributes were analyzed in samples collected from the layers $0-5$ and 5-20 cm and the microbial activity evaluated by hydrolysis of fluorescein diacetate, in samples collected from the 0-10 cm layer. The organic fragment mass was evaluated at different depths. Ant communities with activity on the soil surface were considered for evaluation. The principal component analysis was used to compare the sites. The organic compartment attributes (organic $C$, dissolved organic $C$ and organic fragments) were very sensitive to modifications in the vegetation cover at Caju sites, isolating the native forest sites from the disturbed ones and the ginger-grass site from the coconut palm and brushwood sites. Soil solution attributes influenced by sea-salt spray (electric conductivity, $K, \mathrm{Na}$ and $\mathrm{Mg}$ ) distinguished the Pirambu from the Caju sites. The ant groups had a high level of specialization. Canonical correspondence analysis indicated a low percentage of variance of distribution of these groups and isolated the forest sites from other uses, indicating the existence of other attributes to be considered for distribution.
\end{abstract}

Index terms: Spodosols, Quartzarenic Neosols (Entisols), soil fauna, multivariate analyses.

\section{INTRODUÇÃO}

A palavra restinga pode assumir vários significados, sendo aqui referida como todos os depósitos arenosos litorâneos (Suguio, 1998) - ecossistemas de presença marcante ao longo da costa brasileira. Os solos de restinga, formados por pacotes areno-quartzosos, apresentam uma capacidade de suporte limitada. A muito baixa capacidade de reter água e nutrientes faz com que as formas orgânicas e a biota exerçam papel crucial na fertilidade desses solos (Manlay et al., 2000). Na biota, as formigas (Hymenoptera: Formicidae) representam o grupo dominante de invertebrados em termos de biomassa e de riqueza de espécies (Agosti et al., 2000) e podem causar grande impacto em outros componentes da fauna e da flora (Wirth et al., 2003). Nos sistemas agrícolas, as formigas podem ser pragas ou agentes de controle biológico e ajudam a moldar as comunidades ecológicas por meio de interações com espécies, incluindo a competição (Lobry de Bruyn, 1999).

Embora a vegetação de restinga tenha seus remanescentes protegidos por lei (são parte integrante do bioma Mata Atlântica), a pressão pelo uso agrícola e, sobretudo, pelo uso urbano desses ambientes tem sido constante em muitas regiões e municípios brasileiros (Cerqueira, 2000). Em muitas áreas, esse uso tem origem nas comunidades indígenas préhistóricas ou nos primórdios da colonização local. O uso agrícola de áreas de restinga é, de modo geral, restrito a culturas adaptadas a fortes limitações por deficiência de nutrientes e, ou, água, por vezes associadas à deficiência de oxigênio, durante o período chuvoso, que, no caso de Sergipe, ocorre no outono- 
inverno. Em Sergipe destacam-se plantios de coqueiro gigante (mercado de coco seco para a indústria), populações nativas de mangabeira, pastagens nativas com baixa capacidade de suporte e pequenas roças de culturas diversas (Gomes et al., 2007).

Considerando a importância que a interação de grupos funcionais e propriedades abióticas do solo assume na sustentabilidade desses ecossistemas, o presente estudo compara algumas situações e usos de restinga no Estado de Sergipe, buscando estabelecer relações entre atributos químicos do solo, resíduos orgânicos e atividade da microbiota do solo e destes com a ocorrência de espécies de formigas.

\section{MATERIAL E MÉTODOS}

Duas áreas de restinga foram selecionadas no Estado de Sergipe: (1) Fazenda Caju da Embrapa (área Caju, município de Itaporanga D’Ajuda); e (2) Mata das Traíras (área Pirambu, município de Pirambu) (Figura 1). Na área Caju, os sítios de amostragem englobaram quatro tipos de uso da terra: sítios CM remanescentes de mata com ampla cobertura de árvores e arbustos, pouca vegetação rasteira e muita serapilheira; sítios CG - área desmatada por aproximadamente sete anos, atualmente com ampla cobertura de capim-gengibre (Paspalum maritimum Trin.); sítios CB - área desmatada por 70 anos, atualmente coqueiral do Banco Internacional de Germoplasma do Coco, projeção da copa com cobertura de palha de coqueiro, entrelinhas com cobertura parcial de capim-gengibre e outras gramíneas; e sítios CC - desmatada por 20 anos, onde implantou-se um coqueiral, depois abandonado por 15 anos e atualmente com cobertura de capoeira. Em Pirambu, os sítios amostrados foram de remanescentes de mata, em duas posições: sítios PT - topo de duna; e sítios PS - sopé de nível intermediário de duna. Em cada situação (uso da terra) foram amostrados três sítios, num total de 18 pontos de amostragem. Os solos de todos os sítios foram classificados conforme Embrapa (2006).

Todas as amostragens foram realizadas em setembro-outubro de 2003 e maio de 2004. Amostras de solo de superfície (0-5 cm) e de subsuperfície (5$20 \mathrm{~cm}$ ) foram secas ao ar, destorroadas e passadas em peneiras de malha de $2 \mathrm{~mm}$, para obtenção da terra fina seca ao ar (TFSA). Nessas amostras, foram determinados $\mathrm{pH}$, complexo sortivo, $\mathrm{P}$ disponível e $\mathrm{C}$ orgânico (CO). As análises químicas da TFSA seguiram as recomendações de Embrapa (1997). Foram calculadas a soma de bases trocáveis (SB), a capacidade de troca catiônica (CTC) e as saturações por bases (V) e por $\mathrm{Al}(\mathrm{m})$.

Amostras das mesmas profundidades (0-5 e 5$20 \mathrm{~cm}$ ) foram coletadas e refrigeradas na umidade de campo, para posterior extração da solução do solo (SS). No momento da retirada da SS, uma amostra de

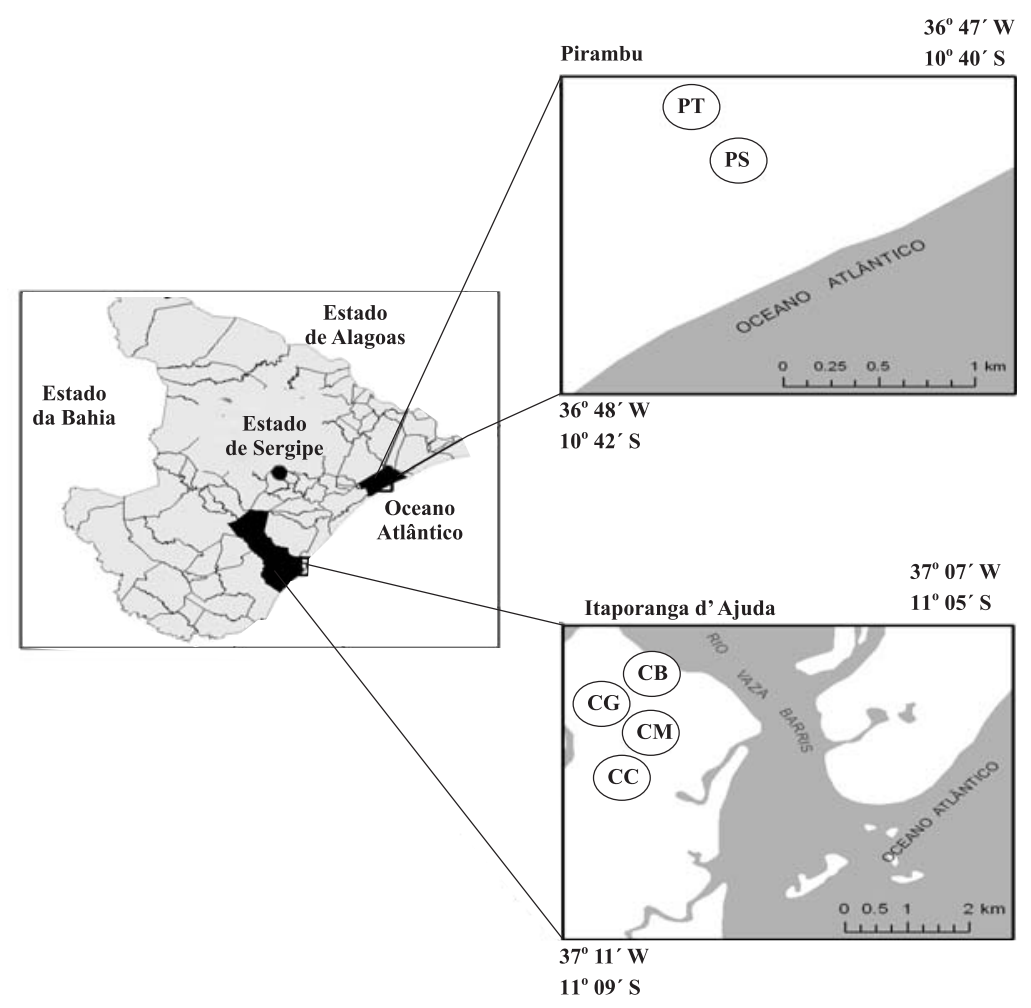

Figura 1. Localização dos sítios estudados, municípios de Itaporanga d'Ajuda e Pirambu, no litoral do Estado de Sergipe. CM: Caju, mata; CG: Caju, capim-gengibre; CB: Caju, coqueiral do banco de germoplasma; CC: Caju, capoeira; PT: Pirambu, mata de topo; Pirambu, mata de sopé. 
aproximadamente $20 \mathrm{~g}$ foi pesada e transferida para tubo de $50 \mathrm{~mL}$ com rosca. Após adição de água destilada suficiente para se alcançar uma relação solo:água 1:1 (incluindo a correção do conteúdo de água da amostra de solo), o tubo foi hermeticamente fechado e agitado por $1 \mathrm{~h}$ em agitador mecânico. Ao final da agitação, a suspensão foi passada em papel-filtro com tamanho de poro de $0,45 \mu \mathrm{m}$ (Rhoades, 1982). Nesse momento foram medidos o $\mathrm{pH}$ e a condutividade elétrica (CE) do extrato, o qual foi então acidificado a pH 2 com ácido nítrico (para evitar ação microbiana, conforme Pérez, 2002) e armazenado sob refrigeração até o momento das leituras de teores de $\mathrm{C}$ orgânico dissolvido (COD) e de elementos por absorção atômica (Al, $\mathrm{Ca}$ e $\mathrm{Mg}$ ), fotometria de chama (K e Na) e colorimetria $(\mathrm{P})$.

Amostras de solo de superfície $(0-10 \mathrm{~cm})$ foram coletadas para determinação da atividade microbiana por hidrólise do diacetato de fluoresceína (FDA) na dose de $100 \mu \mathrm{g}$ (Schnurer \& Rosswall, 1982).

Fragmentos orgânicos retidos entre as malhas de 4 e $2 \mathrm{~mm}(\phi>2-4 \mathrm{~mm})$, na maioria raízes finas e poucos fragmentos de carvão vegetal, foram amostrados nas profundidades de $0-5,5-20$ e $20-40 \mathrm{~cm}$. Fragmentos orgânicos maiores que $4 \mathrm{~mm}(\phi>4 \mathrm{~mm})$, principalmente raízes grossas, foram avaliados por triagem manual em volumes de 1 x 0,5 x 0,40 m. Todos os fragmentos orgânicos coletados no campo foram lavados e secos em estufa ventilada a $60^{\circ} \mathrm{C}$ para posterior pesagem, numa adaptação de Manlay et al. (2000).

$\mathrm{Na}$ avaliação das comunidades de formigas foram utilizadas armadilhas de solo (tipo Doane, contendo álcool $80 \%$ e detergente neutro), para captura de espécimes com atividade na superfície do solo. Em cada sítio foram instaladas três armadilhas, dispostas no centro da área (Della Lucia et al., 1982), permanecendo abertas por 14 dias. Os gêneros e espécies de formigas foram identificados com o auxílio de chaves contidas em revisões taxonômicas (Bolton, 2003) e por meio de comparações com exemplares identificados da coleção do Laboratório de Mirmecologia do Centro de Pesquisas do Cacau/ Comissão Executiva do Plano da Lavoura Cacaueira (CEPEC/CEPLAC), Ilhéus, BA. Nos complexos de espécies com difícil resolução taxonômica, os espécimes coletados foram identificados em morfoespécies, constando o gênero e um número. Esses números, após o nome científico, indicavam formigas do mesmo gênero, porém com grande possibilidade de serem espécies diferentes, conforme seus aspectos morfológicos externos. Uma coleção de referência, com espécimes de cada espécie e localidade amostradas, foi incorporada à coleção do referido laboratório. Os dados de captura foram expressos como frequência de ocorrência de cada morfoespécie no total de armadilhas instaladas dentro de cada sítio.

Os diferentes sítios ambientais foram ordenados por meio de análise de componentes principais (ACP), com base na matriz de correlação das variáveis estudadas, excluindo os dados de fauna. Um diagrama de cluster utilizando distância euclidiana foi construído, procurando classificar os sítios de amostragem quanto à ocorrência das espécies de formiga. A relação entre a frequência de ocorrência das morfoespécies de formigas em cada sítio e as outras variáveis ambientais foi investigada pelo uso da análise de correspondência canônica (ACC). Após análises preliminares, parte das variáveis ambientais foi descartada pela redundância de comportamento e baixa correlação. As espécies de formiga que ocorreram em menos de três armadilhas foram desconsideradas na ACC. O teste de Monte Carlo foi executado para acessar a significância das correlações entre a distribuição da abundância das espécies e as variáveis ambientes (atributos de solo) testadas. Na avaliação dos resultados foram usados os programas PCORD 4.0 (McCune \& Mefford, 1999) e Statistica 7.0 (Statistica, 2004).

\section{RESULTADOS E DISCUSSÃO}

\section{Caracterização ambiental das duas áreas de restinga}

A área do Caju está associada à larga planície litorânea formada no estuário afogado (ria) do rio Vazabarris. Essas rias colmatadas contêm manguezais, terraços arenosos e dunas (Brasil, 1983). Os sítios amostrados correspondem a terraços arenosos de sedimentos fluviomarinhos, todos de relevo plano. Os solos dos sítios estudados são Espodossolos Humilúvicos. Nos sítios CM, CC e CG ocorrem E. Humilúvicos Hiperespessos. Os solos dos sítios CB são E. Humilúvicos Órticos, que apresentam lençol freático e horizonte espódico mais próximos à superfície (em torno de $1,5 \mathrm{~m}$ ), possuindo uma vantagem competitiva do ponto de vista da oferta de água para as plantas, em relação aos outros sítios. Em um dos sítios de mata (CM1), por exemplo, foi constatado o horizonte Bh a 3,89 m de profundidade, junto com a presença do lençol freático local. O nível do lençol freático também é influenciado pela distribuição de chuvas, com elevação deste no outono-inverno chuvoso.

A mata das Traíras, em Pirambu, constitui-se de formações dunares (fixas) que recobrem saprolito da Formação Barreiras (Terciário) (Brasil, 1983). O saprolito apresenta-se localmente amarelado. A cobertura arenosa da duna esparrama-se, sem vegetação, para a baixada litorânea ou para várzeas estreitas barradas por sedimentos marinhos. A distância do limite da elevação até a praia não ultrapassa $1,5 \mathrm{~km}$. A espessura do sedimento arenoso é bastante variável. O relevo varia de plano a forte ondulado. A área de topo com mata apresenta-se plana e com grande espessura do pacote areno-quartzoso e é onde estão localizados os sítios PT. O perfil de solo 
nesta área alcançou a profundidade de $3,1 \mathrm{~m}$, sem sinal de horizonte espódico ( $\mathrm{RQ}$ ou E. Humilúvico Hiperespesso). Passa-se por uma parte de relevo ondulado a forte ondulado, nas encostas da elevação (duna), e alcança-se uma gleba abaciada de relevo suave ondulado a plano, onde o pacote areno-quartzoso é estreito (sítios PS). A posição de paisagem abaciada (sopé de nível intermediário) e o pacote arenoso estreito (por volta de $80 \mathrm{~cm}$ ) fazem os sítios PS serem classificados como Neossolos Regolíticos distróficos e apresentarem um regime de umidade do solo diferenciado, com maior oferta de água para as plantas ao longo do ano.

\section{Compartimentos orgânicos do solo e atividade microbiana}

As variáveis associadas aos compartimentos orgânicos do solo dominam o primeiro eixo da ACP, o qual explica 49,7 \% da variação dos dados, todas com autovetores negativos (Figura 2a). Quatro variáveis destacam-se no segundo eixo (15,1 \% da variação dos dados): COD5-20 cm e FDA100, com autovetores positivos; e $\phi>2-4 \mathrm{~mm} 5-20 \mathrm{~cm}$ e $\phi>2-4 \mathrm{~mm} \mathrm{20}$ $40 \mathrm{~cm}$, com autovetores negativos.

$\mathrm{O}$ primeiro eixo de ordenamento (Figura $2 \mathrm{~b}$ ) formou um gradiente de comportamento entre os sítios, isolando à esquerda as elipses dos sítios sob mata nativa. As elipses dos sítios PT e CM estão relacionadas, de modo geral, às médias elevadas das variáveis de todos os compartimentos orgânicos (Quadros 1, 2 e 3). Os sítios PS ainda apresentam, para a maioria das variáveis dos compartimentos orgânicos, médias superiores às do sítios do Caju com cobertura vegetal alterada, mas as diferenças são menores. Esse comportamento faz com que a elipse dos sítios PS ocupe uma posição central no eixo de ordenamento e apenas ligeiramente mais à esquerda das elipses dos sítios CB e CC.

Na área do Caju, onde foi possível comparar o efeito da mudança da cobertura vegetal nos valores de CO, os sítios sob mata apresentaram valores muito superiores dessa variável. As perdas de CO advindas da substituição da cobertura nativa de uma área são aceleradas pela oxidação dos compartimentos mais lábeis da matéria orgânica e pelas mudanças na quantidade e na qualidade dos resíduos vegetais que retornam ao solo (Lugo \& Brown, 1993). Por sua vez, a maior média de $\mathrm{CO}$ dos sítios sob capoeira do Caju (CC), relativamente aos sítios CG e CB (Quadro 2), pode ser assumida como uma consequência do incremento da quantidade dos resíduos vegetais que retornam ao solo quando uma área anteriormente cultivada é deixada em pousio (15 anos), como também observado por Manlay et al. (2000) em solos arenosos do Senegal. Os sítios PS apresentaram valores de CO baixos, relativamente aos outros sítios sob mata (Quadro 2). Esse comportamento dos sítios PS pode estar relacionado, em parte, a um regime de umidade mais favorável em PS (posição de paisagem abaciada e pacote quartzoso estreito), que acelera o consumo da biomassa orgânica produzida. A quase ausência de serapilheira nos sítios PS corrobora a hipótese apresentada - aspecto presente nas outras situações de mata (CM e PT) com valores de $\mathrm{CO}$ maiores.

Os valores de COD foram tipicamente maiores nos sítios sob mata (Quadro 3). Moore (1989) sugeriu que
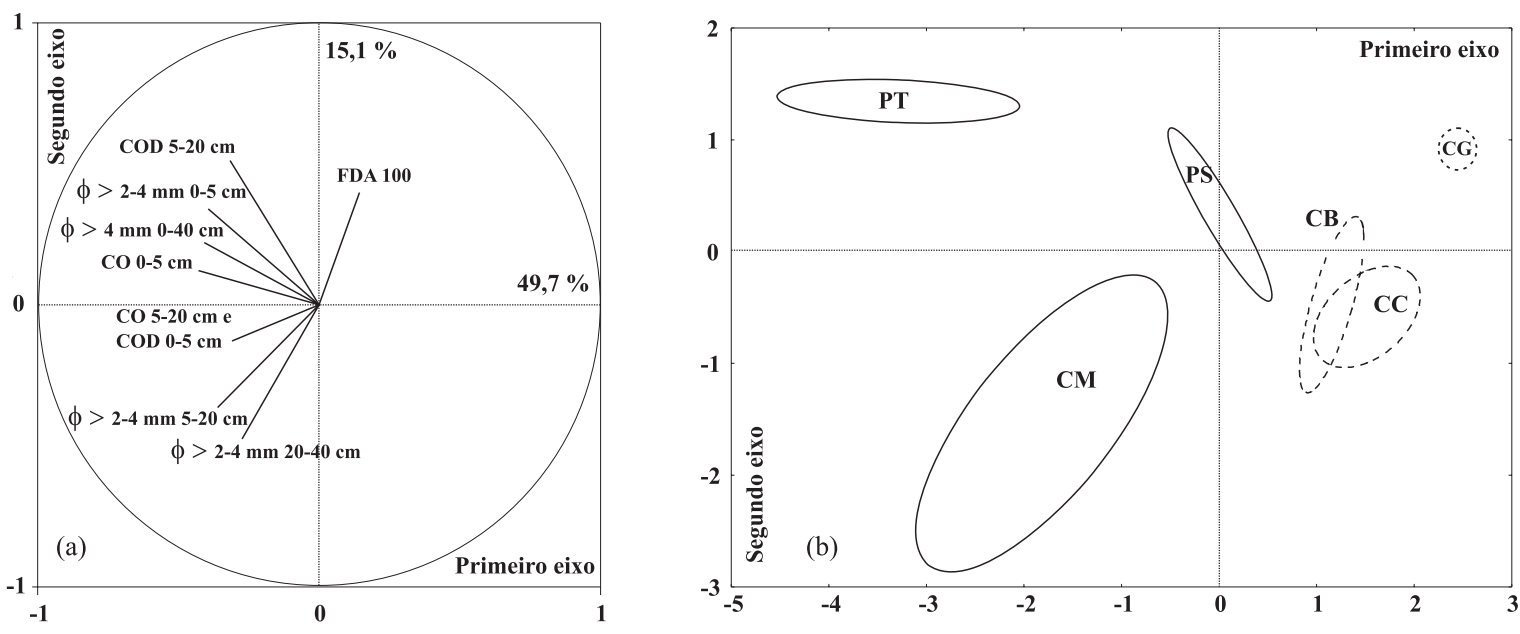

Figura 2. Análise de componentes principais de variáveis associadas a compartimentos orgânicos do solo e atividade microbiana - amostras de 18 sítios de restinga. (a) Círculo de autovetores das variáveis (CO: $\mathrm{C}$ orgânico da terra fina; COD: C orgânico dissolvido; $\phi>2-4 \mathrm{~mm}$ e $\phi>4 \mathrm{~mm}=$ fragmentos orgânicos $>2-$ $4 \mathrm{~mm}$ e $>4 \mathrm{~mm}$, respectivamente; FDA 100 = atividade microbiana pela hidrólise do diacetato de fluoresceína, dose de $100 \mathrm{mg}$, amostras de 0 a $10 \mathrm{~cm}$ de profundidade); (b) Plano de elipses de cada grupo de sítios - CM: Caju, mata; CG: Caju, capim-gengibre; CB: Caju, coqueiral do banco de germoplasma; CC: Caju, capoeira; PT: Pirambu, mata de topo; e PS: Pirambu, mata de sopé. 
Quadro 1. Valores (média \pm erro padrão) de fragmentos orgânicos e da atividade enzimática do diacetato de fluoresceína de amostras de solo dos grupos de sítios de restinga estudados: $\mathrm{CM}=\mathrm{Caju}$ mata; $\mathrm{CG}=\mathrm{Caju}$ capim gengibre; $\mathrm{CB}=\mathrm{Caju}$ coqueiral de banco de germoplasma $\mathbf{C C}=\mathrm{Caju}$ capoeira; $\mathrm{PT}=\mathrm{Pirambu}$ mata de topo; PS = Pirambu mata de sopé. $n=3$

\begin{tabular}{|c|c|c|c|c|c|c|c|}
\hline Variável $^{(1)}$ & Unidade & CM & $\mathrm{CC}$ & CB & CG & PT & PS \\
\hline$\Theta>2 \mathrm{~mm} 0-5 \mathrm{~cm}$ & $\mathrm{~g} \mathrm{dm}^{-3}$ & $9,84 \pm 2,3$ & $3,30 \pm 0,9$ & $7,72 \pm 2,5$ & $5,78 \pm 1,9$ & $30,30 \pm 5,4$ & $12,32 \pm 3,0$ \\
\hline$\Theta>2 \mathrm{~mm} 5-20 \mathrm{~cm}$ & $\mathrm{~g} \mathrm{dm} \mathrm{m}^{-3}$ & $11,95 \pm 4,7$ & $3,82 \pm 0,5$ & $3,85 \pm 1,1$ & $2,03 \pm 0,3$ & $10,17 \pm 0,9$ & $8,01 \pm 0,6$ \\
\hline$\Theta>2 \mathrm{~mm} 20-40 \mathrm{~cm}$ & $\mathrm{~g} \mathrm{dm}^{-3}$ & $5,42 \pm 1,5$ & $0,91 \pm 0,8$ & $4,70 \pm 1,5$ & $0,63 \pm 0,5$ & $3,66 \pm 1,4$ & $2,17 \pm 0,8$ \\
\hline$\Theta>4 \mathrm{~mm} 0-0,4 \mathrm{~m}$ & $\mathrm{~g} \mathrm{dm}^{-3}$ & $11,85 \pm 2,1$ & $3,55 \pm 1,6$ & $6,80 \pm 0,3$ & $2,90 \pm 0,5$ & $15,05 \pm 4,0$ & $9,20 \pm 1,7$ \\
\hline FDA $100 \mu \mathrm{g}$ (densidade ótica) & - & $0,41 \pm 0,01$ & $0,42 \pm 0,02$ & $0,5 \pm 0,05$ & $0,76 \pm 0,03$ & $0,52 \pm 0,09$ & $0,44 \pm 0,09$ \\
\hline
\end{tabular}

(1) $\Theta>2$ mm: fragmentos orgânicos < $4 \mathrm{~mm} \mathrm{e}>2 \mathrm{~mm}$; $\Theta>4 \mathrm{~mm}$ : fragmentos orgânicos > 4 mm; FDA: atividade enzimática do diacetato de fluoresceína.

Quadro 2. Valores (média \pm erro-padrão) de variáveis químicas do solo dos grupos de sítios de restinga estudados - CM: Caju, mata; CG: Caju, capim-gengibre; CB: Caju, coqueiral do banco de germoplasma; CC: Caju, capoeira; PT: Pirambu, mata de topo; e PS: Pirambu, mata de sopé. n = 3

\begin{tabular}{|c|c|c|c|c|c|c|c|}
\hline Variável $^{(1)}$ & Unidade & $\mathrm{CM}$ & $\mathrm{CC}$ & $\mathrm{CB}$ & CG & PT & PS \\
\hline \multicolumn{8}{|c|}{ Profundidade de 0 a $5 \mathrm{~cm}$} \\
\hline $\mathrm{pH}$ & - & $4,9 \pm 0,2$ & $5,1 \pm 0,04$ & $5,7 \pm 0,3$ & $5,4 \pm 0,1$ & $4,9 \pm 0,3$ & $5,4 \pm 0,1$ \\
\hline $\mathrm{CO}$ & $\mathrm{g} \mathrm{kg}^{-1}$ & $30,07 \pm 2,61$ & $20,01 \pm 2,74$ & $16,05 \pm 1,27$ & $11,12 \pm 0,77$ & $47,56 \pm 7,55$ & $18,27 \pm 2,77$ \\
\hline $\mathrm{P}$ & $\mathrm{mg} \mathrm{kg}^{-1}$ & $3,32 \pm 0,12$ & $1,58 \pm 0,17$ & $13,38 \pm 2,16$ & $1,78 \pm 0,04$ & $2,58 \pm 1,06$ & $1,45 \pm 0,34$ \\
\hline $\mathrm{K}$ & $\mathrm{cmol}_{\mathrm{c}} \mathrm{dm}^{-3}$ & $0,06 \pm 0,01$ & $0,03 \pm 0$ & $0,09 \pm 0,01$ & $0,03 \pm 0$ & $0,1 \pm 0,02$ & $0,08 \pm 0$ \\
\hline $\mathrm{Na}$ & $\mathrm{cmol}_{\mathrm{c}} \mathrm{dm}^{-3}$ & $0,83 \pm 0,17$ & $0,5 \pm 0,05$ & $0,48 \pm 0,03$ & $0,47 \pm 0,01$ & $1,75 \pm 0,25$ & $1,12 \pm 0,01$ \\
\hline $\mathrm{Ca}$ & $\mathrm{cmol}_{\mathrm{c}} \mathrm{dm}^{-3}$ & $1,48 \pm 0,11$ & $1,2 \pm 0,35$ & $1,41 \pm 0,22$ & $0,94 \pm 0,07$ & $3,25 \pm 0,69$ & $1,56 \pm 0,34$ \\
\hline $\mathrm{Mg}$ & $\mathrm{cmol}_{\mathrm{c}} \mathrm{dm}^{-3}$ & $0,69 \pm 0,12$ & $0,52 \pm 0,05$ & $0,97 \pm 0,25$ & $0,63 \pm 0,05$ & $1,43 \pm 0,2$ & $0,75 \pm 0,1$ \\
\hline $\mathrm{Al}$ & $\mathrm{cmol}_{\mathrm{c}} \mathrm{dm}^{-3}$ & $0,57 \pm 0,19$ & $0,2 \pm 0,04$ & $0,03 \pm 0,02$ & $0,04 \pm 0,01$ & $0,51 \pm 0,2$ & $0,17 \pm 0,04$ \\
\hline SB & $\mathrm{cmol}_{\mathrm{c}} \mathrm{dm}^{-3}$ & $3,07 \pm 0,39$ & $2,25 \pm 0,39$ & $2,95 \pm 0,24$ & $2,08 \pm 0,06$ & $6,52 \pm 0,74$ & $3,51 \pm 0,44$ \\
\hline CTC & $\mathrm{cmol}_{\mathrm{c}} \mathrm{dm}^{-3}$ & $11,8 \pm 2,86$ & $7,08 \pm 1,79$ & $5,75 \pm 0,22$ & $5,45 \pm 0,78$ & $22,27 \pm 4,74$ & $8,5 \pm 1,19$ \\
\hline $\mathrm{V}$ & $\%$ & $31 \pm 6$ & $38 \pm 5$ & $53 \pm 5$ & $45 \pm 2$ & $33 \pm 9$ & $41 \pm 1$ \\
\hline $\mathrm{m}$ & $\%$ & $16 \pm 5$ & $9 \pm 4$ & $1 \pm 1$ & $2 \pm 0$ & $7 \pm 2$ & $6 \pm 2$ \\
\hline \multicolumn{8}{|c|}{ Profundidade de 5 a $20 \mathrm{~cm}$} \\
\hline $\mathrm{pH}$ & & $4,6 \pm 0,1$ & $5,0 \pm 0,05$ & $5,3 \pm 0,4$ & $5,2 \pm 0,1$ & $4,9 \pm 0,2$ & $5,2 \pm 0,1$ \\
\hline $\mathrm{CO}$ & $\mathrm{g} \mathrm{kg}^{-1}$ & $20,59 \pm 2,25$ & $16,05 \pm 3,52$ & $8,02 \pm 0,84$ & $9,86 \pm 1,26$ & $20,11 \pm 4,81$ & $9,67 \pm 0,42$ \\
\hline $\mathrm{P}$ & $\mathrm{mg} \mathrm{kg}^{-1}$ & $2,6 \pm 0,48$ & $2,07 \pm 0,14$ & $8 \pm 1,5$ & $1,52 \pm 0,16$ & $1,72 \pm 0,35$ & $0,88 \pm 0,16$ \\
\hline $\mathrm{K}$ & $\mathrm{cmol}_{\mathrm{c}} \mathrm{dm}^{-3}$ & $0,03 \pm 0$ & $0,02 \pm 0$ & $0,06 \pm 0,01$ & $0,03 \pm 0$ & $0,04 \pm 0,01$ & $0,06 \pm 0,01$ \\
\hline $\mathrm{Na}$ & $\mathrm{cmol}_{\mathrm{c}} \mathrm{dm}^{-3}$ & $0,65 \pm 0,09$ & $0,45 \pm 0,06$ & $0,37 \pm 0,01$ & $0,4 \pm 0,03$ & $0,98 \pm 0,1$ & $0,97 \pm 0,12$ \\
\hline $\mathrm{Ca}$ & $\mathrm{cmol}_{\mathrm{c}} \mathrm{dm}^{-3}$ & $0,36 \pm 0,03$ & $0,55 \pm 0,23$ & $0,58 \pm 0,09$ & $0,55 \pm 0,06$ & $0,87 \pm 0,4$ & $0,57 \pm 0,24$ \\
\hline $\mathrm{Mg}$ & $\mathrm{cmol}_{\mathrm{c}} \mathrm{dm}^{-3}$ & $0,35 \pm 0,07$ & $0,35 \pm 0,14$ & $0,39 \pm 0,06$ & $0,36 \pm 0,05$ & $0,42 \pm 0,06$ & $0,35 \pm 0,07$ \\
\hline $\mathrm{Al}$ & $\mathrm{cmol}_{\mathrm{c}} \mathrm{dm}^{-3}$ & $0,8 \pm 0,21$ & $0,52 \pm 0,06$ & $0,19 \pm 0,1$ & $0,17 \pm 0,07$ & $0,57 \pm 0,16$ & $0,34 \pm 0,1$ \\
\hline SB & $\mathrm{cmol}_{\mathrm{c}} \mathrm{dm}^{-3}$ & $1,38 \pm 0,18$ & $1,38 \pm 0,42$ & $1,41 \pm 0,16$ & $1,33 \pm 0,02$ & $2,31 \pm 0,43$ & $1,94 \pm 0,43$ \\
\hline CTC & $\mathrm{cmol}_{\mathrm{c}} \mathrm{dm}^{-3}$ & $9,22 \pm 2,34$ & $6,29 \pm 1,52$ & $3,52 \pm 0,37$ & $5,59 \pm 1,02$ & $9,57 \pm 1,48$ & $5,47 \pm 0,42$ \\
\hline $\mathrm{V}$ & $\%$ & $19 \pm 3$ & $24 \pm 5$ & $40 \pm 6$ & $30 \pm 7$ & $28 \pm 7$ & $34 \pm 5$ \\
\hline $\mathrm{m}$ & $\%$ & $34 \pm 8$ & $28 \pm 6$ & $13 \pm 7$ & $11 \pm 5$ & $21 \pm 5$ & $16 \pm 5$ \\
\hline
\end{tabular}

(1) CO: C orgânico; SB: soma de bases; CTC: capacidade de troca catiônica; V: saturação por bases; m: saturação por Al.

não existe um padrão de comportamento para os efeitos do desmatamento nos níveis de COD. Por um determinado espaço de tempo, que depende das condições de cada local, os níveis de COD podem aumentar pela decomposição da serapilheira e da matéria orgânica do solo (McLaughlin et al., 1996). Após esse período, 
Quadro 3. Valores (média \pm erro-padrão) de variáveis da solução do solo dos grupos de sítios de restinga estudados - CM: Caju, mata; CG: Caju, capim-gengibre; CB: Caju, coqueiral do banco de germoplasma; CC: Caju, capoeira; PT: Pirambu, mata de topo; e PS: Pirambu, mata de sopé. n = 3

\begin{tabular}{|c|c|c|c|c|c|c|c|}
\hline Variável $^{(1)}$ & Unidade & $\mathbf{C M}$ & $\mathrm{CC}$ & CB & $\mathbf{C G}$ & PT & PS \\
\hline \multicolumn{8}{|c|}{ Profundidade de 0 a $5 \mathrm{~cm}$} \\
\hline $\mathrm{pH}$ & - & $7,5 \pm 1,1$ & $6,4 \pm 0,1$ & $6,8 \pm 0,2$ & $5,5 \pm 0,1$ & $4,8 \pm 0,1$ & $4,9 \pm 0,1$ \\
\hline $\mathrm{CE}$ & $\mu \mathrm{S} \mathrm{cm}^{-1}$ & $91,93 \pm 25,62$ & $43,07 \pm 4,94$ & $74,6 \pm 8,54$ & $39,5 \pm 2,4$ & $228,17 \pm 49,92$ & $144,73 \pm 10,81$ \\
\hline $\mathrm{P}$ & $\mathrm{mg} \mathrm{L}^{-1}$ & $0,25 \pm 0,17$ & $1,32 \pm 0,29$ & $0,46 \pm 0,23$ & $1,12 \pm 0,46$ & $0,04 \pm 0$ & $0,04 \pm 0$ \\
\hline $\mathrm{K}$ & $\mathrm{mg} \mathrm{L}^{-1}$ & $1,81 \pm 0,16$ & $4,04 \pm 1,21$ & $3,26 \pm 0,66$ & $2,32 \pm 0,5$ & $8,84 \pm 1,17$ & $7,73 \pm 0,67$ \\
\hline $\mathrm{Na}$ & $\mathrm{mg} \mathrm{L}^{-1}$ & $7,94 \pm 3,29$ & $4,35 \pm 0,37$ & $4,23 \pm 0,3$ & $4,77 \pm 1,14$ & $20,52 \pm 4,09$ & $14,51 \pm 0,79$ \\
\hline $\mathrm{Ca}$ & $\mathrm{mg} \mathrm{L}^{-1}$ & $2,39 \pm 0,95$ & $6,78 \pm 6$ & $4,74 \pm 0,98$ & $0,63 \pm 0,12$ & $5,4 \pm 1,7$ & $2,5 \pm 0,24$ \\
\hline $\mathrm{Mg}$ & $\mathrm{mg} \mathrm{L}^{-1}$ & $0,78 \pm 0,29$ & $1,48 \pm 0,52$ & $1,48 \pm 0,17$ & $0,71 \pm 0,29$ & $3,3 \pm 1,63$ & $2,42 \pm 0,38$ \\
\hline $\mathrm{Al}$ & $\mathrm{mg} \mathrm{L}^{-1}$ & $0,18 \pm 0,04$ & $0,25 \pm 0,04$ & $0,36 \pm 0,19$ & $0,19 \pm 0,01$ & $0,19 \pm 0,08$ & $0,18 \pm 0,01$ \\
\hline COD & $\mathrm{mg} \mathrm{L}^{-1}$ & $35,97 \pm 20,74$ & $5,42 \pm 1,47$ & $8,12 \pm 2,37$ & $6,41 \pm 1,75$ & $21,23 \pm 4,44$ & $15,11 \pm 1,12$ \\
\hline \multicolumn{8}{|c|}{ Profundidade de 5 a $20 \mathrm{~cm}$} \\
\hline $\mathrm{pH}$ & - & $5,9 \pm 1$ & $6,4 \pm 0,3$ & $6,8 \pm 0,3$ & $5,8 \pm 0,5$ & $4,9 \pm 0,1$ & $5,2 \pm 0,1$ \\
\hline $\mathrm{CE}$ & $\mu \mathrm{S} \mathrm{cm}^{-1}$ & $54,33 \pm 6,43$ & $31,63 \pm 4,5$ & $43,8 \pm 10,78$ & $32,27 \pm 1,27$ & $117,87 \pm 15,21$ & $101,67 \pm 17,15$ \\
\hline $\mathrm{P}$ & $\mathrm{mg} \mathrm{L}^{-1}$ & $0,1 \pm 0,06$ & $0,52 \pm 0,08$ & $0,38 \pm 0,3$ & $0,22 \pm 0,15$ & $0,12 \pm 0,08$ & $0,04 \pm 0$ \\
\hline $\mathrm{K}$ & $\mathrm{mg} \mathrm{L}^{-1}$ & $2,53 \pm 0,5$ & $2,54 \pm 1,45$ & $2,69 \pm 0,62$ & $1,75 \pm 0,63$ & $4,72 \pm 0,33$ & $4,79 \pm 0,7$ \\
\hline $\mathrm{Na}$ & $\mathrm{mg} \mathrm{L}^{-1}$ & $5,2 \pm 1,65$ & $3,02 \pm 0,11$ & $5,6 \pm 1,4$ & $3,76 \pm 0,38$ & $13,02 \pm 2,34$ & $12,2 \pm 2,09$ \\
\hline $\mathrm{Ca}$ & $\mathrm{mg} \mathrm{L}^{-1}$ & $1,21 \pm 0,56$ & $6,47 \pm 6,32$ & $0,6 \pm 0,45$ & $0,32 \pm 0,06$ & $1,62 \pm 0,33$ & $1,7 \pm 0,08$ \\
\hline $\mathrm{Mg}$ & $\mathrm{mg} \mathrm{L}^{-1}$ & $0,54 \pm 0,38$ & $0,47 \pm 0,3$ & $0,47 \pm 0,19$ & $0,17 \pm 0,08$ & $1,12 \pm 0,29$ & $1,64 \pm 0,46$ \\
\hline $\mathrm{Al}$ & $\mathrm{mg} \mathrm{L}^{-1}$ & $0,07 \pm 0,03$ & $0,28 \pm 0,04$ & $0,25 \pm 0,14$ & $0,07 \pm 0,05$ & $0,33 \pm 0,01$ & $2,02 \pm 1,76$ \\
\hline COD & $\mathrm{mg} \mathrm{L}^{-1}$ & $5,62 \pm 1,51$ & $1,32 \pm 0,68$ & $3,53 \pm 0,59$ & $3,99 \pm 0,37$ & $16,47 \pm 2,28$ & $10,98 \pm 3,14$ \\
\hline
\end{tabular}

(1) $\mathrm{CE}$ : condutividade elétrica; COD: C orgânico dissolvido.
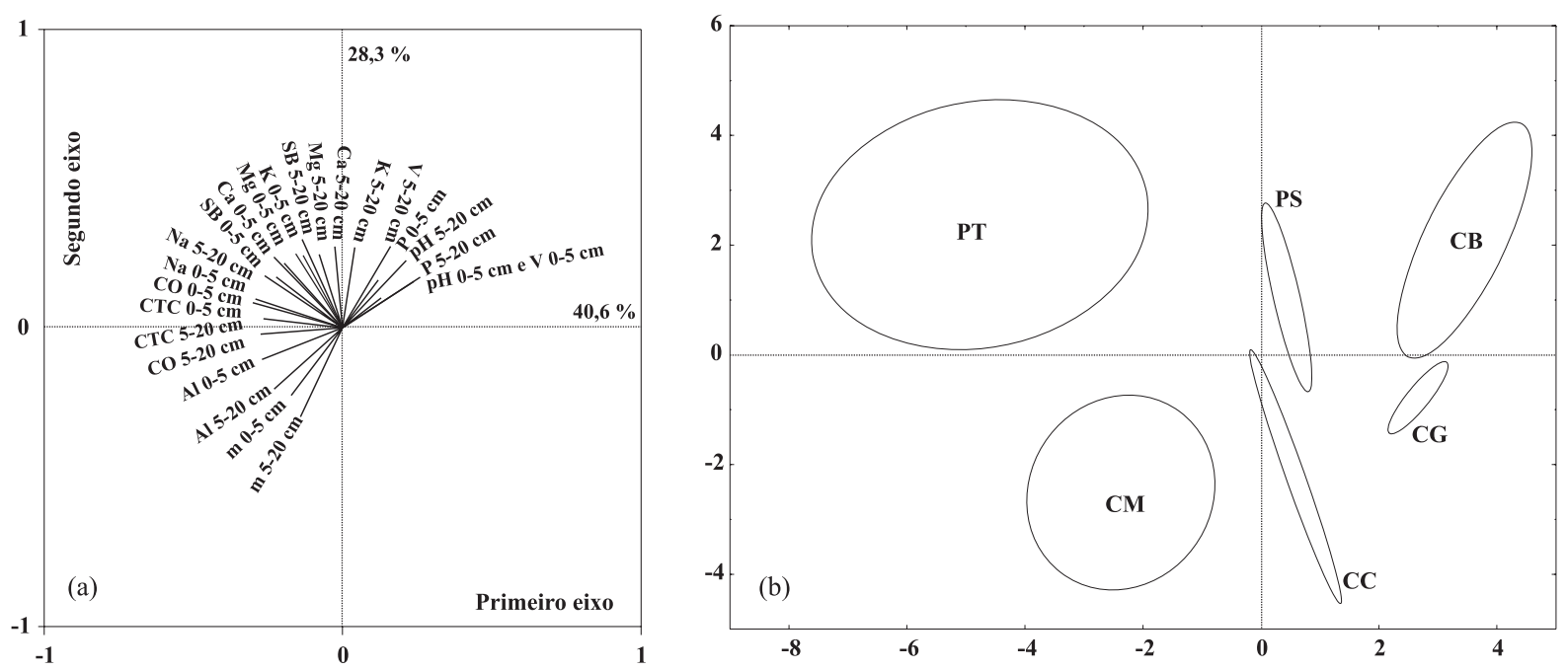

Figura 3. Análise de componentes principais de atributos químicos de rotina do solo-amostras de 18 sítios de restinga. (a) Círculo de autovetores das variáveis (pH, CO: C orgânico, P, K, Na, Ca, Mg, Al, SB: soma de bases, CTC: capacidade de troca catiônica, V: saturação por bases, m: saturação por Al; amostras de 0 a 5 e 5 a 20 cm de profundidade); (b) Plano de elipses de cada grupo de sítios: CM: Caju, mata; CG: Caju, capim-gengibre; CB: Caju, coqueiral do banco de germoplasma; CC: Caju, capoeira; PT: Pirambu, mata de topo; PS: Pirambu, mata de sopé.

entretanto, a decomposição de matéria orgânica é desacelerada (novo patamar de equilíbrio) e os níveis de COD são reduzidos (Moore, 1989). Para os sítios alterados aqui estudados, a mudança da cobertura vegetal já tinha ocorrido há pelo menos sete anos e, ainda, deve-se considerar que solos areno-quartzosos oferecem, relativamente aos de textura mais fina, pouca proteção à sua fração orgânica (Feller \& Beare, 1997). 
Sítios CB sobressaíram na biomassa de $\phi>2-4 \mathrm{~mm}$ 20-40 cm (Quadro 1), onde se concentra a maior parte do sistema radicular do coqueiro-anão (Cintra et al., 1992). Nessa profundidade, apenas CM teve maior média para $\phi>2-4 \mathrm{~mm}$ do que $\mathrm{CB}$. A posição mais à direita no eixo de ordenamento da elipse dos sítios CG foi muito influenciada pelo tipo de sistema radicular das gramíneas, que produz uma biomassa mais superficial e mais leve (Manlay et al., 2000).

A atividade microbiana inferida pela FDA apresentou média bem mais elevada nos sítios CG (Quadro 1), relativamente às outras coberturas estudadas, o que deixou a elipse do grupo na parte superior do segundo eixo de ordenamento. Valores mais elevados de atividade enzimática nas áreas com coberturas de gramíneas, relativamente a outros usos, são corroborados por vários trabalhos (Haynes \& Tregurtha, 1999; Nsabimana et al., 2004; Sicardi et al., 2004), sobretudo quando comparados com cultivos anuais (Udawatta et al., 2008). Além disso, Bandick \& Dick (1999) realçam a importância da grande extensão e da capilaridade do sistema radicular das gramíneas no incremento da atividade microbiana e enzimática - o que eles chamam de efeito rizosfera.

\section{Atributos químicos do solo - terra fina seca ao ar}

Os sítios sob remanescentes de mata PT e CM posicionaram-se à esquerda do primeiro eixo do diagrama de ordenação da ACP (Figura 3). Eles foram influenciados, principalmente, pelos maiores teores de CO e CTC, relativamente aos outros usos estudados (Quadro 2). Em um substrato pobre, como a matriz silicosa dos solos de restinga, a matéria orgânica funciona, basicamente, como única fonte de acidez (Gomes et al., 1998), influenciando os valores de CTC por meio da acidez potencial a $\mathrm{pH} 7(\mathrm{H}+\mathrm{Al})$. Corroborando esse aspecto, $\mathrm{CO}, \mathrm{CTC}$ e $\mathrm{Al}$ possuem autovetores negativos de destaque no primeiro eixo da ACP (Figura 3a).

Os valores relativamente elevados de soma de bases dos sítios PT e PS (Quadro 2) podem estar expressando uma forte influência do spray marinho na área de Pirambu, comparada com a área de Caju. Essa influência relaciona-se com a maior proximidade dos sítios de Pirambu da linha da praia e também foi encontrada por Whipkey et al. (2000) para solos vulcânicos do litoral do Havaí. O Na acumula-se, relativamente ao $\mathrm{K}$, em face de sua maior riqueza nesses sprays (Ming \& Russel, 2001). Os sítios PS, além dessa influência, apresentam, entre as situações de mata, os menores teores de CO (Quadro 2). Essas características combinadas parecem ser a razão de uma reação do solo mais próxima à neutralidade e de um maior V dos sítios PS, em comparação com outros sob mata.

Os maiores valores de $\mathrm{P}$ dos sítios $\mathrm{CB}$ podem ser reflexo das adubações que a área cultivada com coqueiro vem recebendo, mesmo com a amostragem feita na entrelinha do coqueiral. A matriz quartzosa dos solos de restinga, não fixando o $\mathrm{P}$ adicionado, e a baixa mobilidade do elemento também podem explicar os maiores valores de $\mathrm{P}$ dos sítios $\mathrm{CB}$, visto que a quantidade de argila é a principal responsável pela variação do fator capacidade de $\mathrm{P}$ dos solos (Boschetti A. et al., 1998).
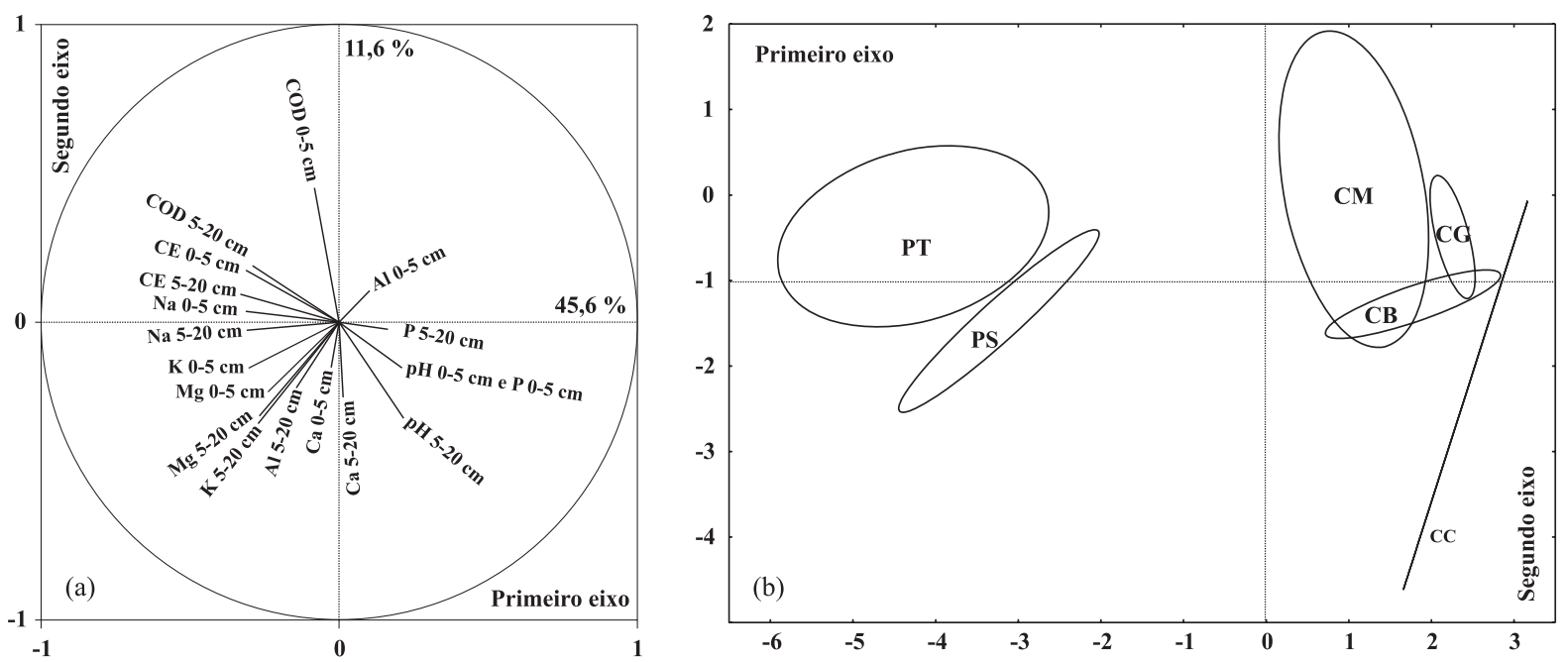

Figura 4. Análise de componentes principais de variáveis químicas da solução do solo-amostras de 18 sítios de restinga. (a) Círculo de autovetores das variáveis (pH, CE: condutividade elétrica, $\mathrm{P}, \mathrm{K}, \mathrm{Na}, \mathrm{Ca}, \mathrm{Mg}, \mathrm{Al}$ e COD: C orgânico dissolvido; amostras de 0 a 5 e 5 a $20 \mathrm{~cm}$ de profundidade); (b) Plano de elipses de cada grupo de sítios: CM: Caju, mata; CG: Caju, capim-gengibre; CB: Caju, coqueiral do banco de germoplasma; CC: Caju, capoeira; PT: Pirambu, mata de topo; PS: Pirambu, mata de sopé. 


\section{Atributos químicos da solução do solo}

O primeiro eixo da ACP, importante na explicação da variação dos dados (autovalor de 45,6 \% contra $11,6 \%$ do segundo eixo), aproximou as elipses dos sítios PT e PS e os separou de todos os sítios restantes (Figura 4), inclusive dos remanescentes de mata do Caju (CM). Os principais vetores do primeiro eixo foram $\mathrm{CE}$, e concentrações de $\mathrm{K}, \mathrm{Na}$ e $\mathrm{Mg}$ para as duas profundidades amostradas e o COD 5-20 cm, todos com valores médios nos conjuntos de sítios sob mata de Pirambu (PT e PS) sobressaindo em relação às médias de todos os outros grupos (Quadro 3). Assim, as variáveis da solução do solo, no seu conjunto, foram muito mais sensíveis ao local que aos diferentes usos da terra. Aqui, a provável influência do spray sobre alguns atributos (Whipkey et al., 2000), principalmente $\mathrm{CE}, \mathrm{K}$ e Na, aspecto já comentado para os valores $\mathrm{SB}$, aparece de forma mais clara.

\section{Relações entre ocorrência de formigas e atributos do solo}

Foram coletadas 71 espécies de formigas, distribuídas em 28 gêneros e seis subfamílias (dados parcialmente apresentados no Quadro 4), predominando a guilda de formigas omnívoras de serapilheira-solo, muitas das quais são estrategistas oportunistas (Delabie et al., 2000). A diversidade de formigas encontrada foi similar ao relatado por Bonnet \& Lopes (1993) para restinga em Florianópolis (SC), porém menor que a verificada por Vargas et al. (2007) no mesmo tipo de ambiente, em Marambaia (RJ). Essas diferenças estariam relacionadas aos planos de amostragem da mirmecofauna e às características biogeográficas regionais (Hölldobler \& Wilson, 1990; Agosti et al., 2000).

Das 71 espécies, 49 ocorreram em menos de três sítios e foram desconsideradas na ACC (Figura 5). O autovalor produzido pelo primeiro eixo da $\mathrm{ACC}(0,678)$ é elevado, e o produzido pelo segundo eixo $(0,362)$ é médio a baixo, indicando a predominância de gradientes médios a longos (Ter Braak, 1995), ou seja, determinadas espécies de formiga tendem a não ocorrer ao longo de todo o gradiente ambiental, ficando fixas em poucas situações. Apenas formigas dos gêneros Camponotus, Ectatomma, Solenopsis e Pheidole estiveram presentes em todos os sítios de restinga (Quadro 4), com outros gêneros, a maioria, ocorrendo em ambientes específicos. A adaptação ecológica dos gêneros Camponotus, Pheidole e Solenopsis é uma consequência da grande diversidade de espécies, da extensão de distribuição geográfica e da abundância na região neotropical desses gêneros (Wilson, 1976). Já o gênero Ectatomma apresenta, de modo geral, espécies predadoras de outros artrópodes e altamente exigentes quanto à qualidade ambiental, embora também possam ocorrer espécies abundantes em

Quadro 4. Frequência de ocorrência de 22 espécies de formiga (de um total de 71) nas áreas amostradas. A frequência refere-se à presença da espécie nas armadilhas de cada grupo de sítios (três sítios por combinação de área e uso da terra, com três armadilhas por sítio, $n=9$ ) e está apresentada para as espécies que ocorreram em pelo menos três sítios dos 18 amostrados

\begin{tabular}{|c|c|c|c|c|c|c|c|}
\hline \multicolumn{2}{|l|}{ Espécie } & \multicolumn{6}{|c|}{ Grupo de sítios $^{(1)}$} \\
\hline Nome & Código & CM & CG & CB & $\mathbf{C C}$ & PT & PS \\
\hline Ectatomma suzanae & $\mathrm{Es}$ & 52 & 0 & 0 & 11 & & 22 \\
\hline Ectatomma muticum & Em & 3 & 86 & 79 & 100 & 22 & 0 \\
\hline Camponotus spp. & $\mathrm{Cs}$ & 7 & 7 & 31 & 11 & 22 & 11 \\
\hline Solenopsis sp.1 & $\mathrm{S} 1$ & 0 & 0 & 21 & 0 & 0 & 0 \\
\hline Solenopsis sp.2 & $\mathrm{S} 2$ & 14 & 31 & 24 & 89 & 0 & 0 \\
\hline Solenopsis sp.3 & S3 & 7 & 0 & 14 & 0 & 0 & 22 \\
\hline Solenopsis sp.4 & $\mathrm{S} 4$ & 14 & 5 & 3 & 0 & 33 & 11 \\
\hline Solenopsis globularia & $\mathrm{Sg}$ & 21 & 7 & 3 & 22 & 0 & 0 \\
\hline Solenopsis tridens & St & 0 & 0 & 14 & 11 & 0 & 0 \\
\hline Pheidole sp.1 & $\mathrm{P} 1$ & 17 & 0 & 35 & 0 & 0 & 0 \\
\hline Pheidole sp.2 & P2 & 55 & 0 & 5 & 22 & 33 & 33 \\
\hline Pheidole sp.3 & P3 & 14 & 27 & 10 & 22 & 11 & 44 \\
\hline Pheidole sp.4 & $\mathrm{P} 4$ & 14 & 7 & 3 & 22 & 0 & 0 \\
\hline Pheidole sp.5 & P5 & 3 & 3 & 3 & 0 & 0 & 0 \\
\hline Dorymyrmex spp. & Ds & 0 & 14 & 17 & 78 & 0 & 0 \\
\hline Brachymyrmex sp.1 & B1 & 0 & 24 & 10 & 89 & 0 & 0 \\
\hline Brachymyrmex sp.2 & $\mathrm{B} 2$ & 0 & 3 & 0 & 11 & 0 & 0 \\
\hline Brachymyrmex sp.3 & B3 & 0 & 7 & 0 & 22 & 0 & 0 \\
\hline Neivamyrmex sp. & $\mathrm{Ns}$ & 3 & 3 & 0 & 22 & 0 & 0 \\
\hline Wasmannia auropunctata & $\mathrm{Wa}$ & 0 & 0 & 7 & 11 & 0 & 0 \\
\hline Atta laevigata & $\mathrm{Al}$ & 3 & 62 & 38 & 33 & 11 & 0 \\
\hline Diponera quadriceps & $\mathrm{Dq}$ & 0 & 0 & 0 & 0 & 11 & 22 \\
\hline
\end{tabular}

(1) CM: Caju, mata; CG: Caju, capim-gengibre; CB: Caju, coqueiral do banco de germoplasma; CC: Caju, capoeira; PT: Pirambu, mata de topo; OS: Pirambu, mata de sopé. 

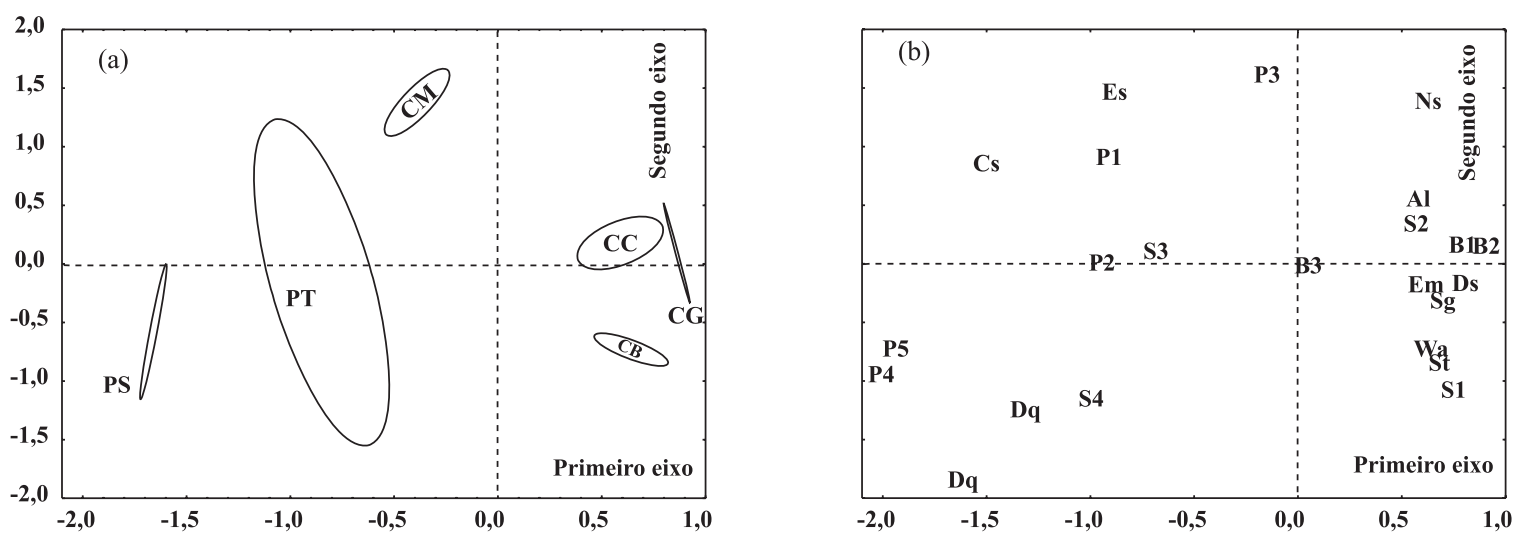

Figura 5. Análise de correspondência canônica: diagramas de ordenação mostrando a distribuição dos 18 sítios de restinga (a) e de 22 espécies de formiga capturadas nas armadilhas de solo (b) nos dois primeiros eixos. Valores dos vetores dos atributos de solo usados (17 variáveis) estão no quadro 5. Grupos de sítios em (a) como elipses: CM: Caju, mata; CG: Caju, capim-gengibre; CB: Caju, coqueiral do banco de germoplasma; CC: Caju, capoeira; PT: Pirambu, mata de topo; PS: Pirambu, mata de sopé. Espécies de formigas representadas por códigos do quadro $4 \mathrm{em}(\mathrm{B})$.

Quadro 5. Correlações dos atributos de solo com os dois primeiros eixos da análise de correspondência canônica, envolvendo 18 sítios de restinga e 22 espécies de formiga capturadas em armadilhas de solo. Diagramas de ordenação estão na figura 5

\begin{tabular}{llll}
\hline \multicolumn{1}{c}{ Variável } & Profundidade & Eixo 1 & Eixo 2 \\
\hline Fragmentos orgânicos $<2-4 \mathrm{~mm}$ & $\mathrm{~cm}$ & & $-0,055$ \\
Fragmentos orgânicos $<2-4 \mathrm{~mm}$ & $0-5$ & $-0,586$ & 0,345 \\
Fragmentos orgânicos $>4 \mathrm{~mm}$ & $5-20$ & $-0,591$ & 0,237 \\
C orgânico & $0-40$ & $-0,666$ & 0,270 \\
C orgânico & $0-5$ & $-0,468$ & 0,488 \\
Al trocável & $5-20$ & $-0,230$ & 0,568 \\
Al trocável & $0-5$ & $-0,409$ & 0,647 \\
Capacidade de troca catiônica & $5-20$ & $-0,257$ & 0,280 \\
Capacidade de troca catiônica & $0-5$ & $-0,510$ & 0,424 \\
C orgânico dissolvido (solução do solo) & $5-20$ & $-0,341$ & 0,305 \\
C orgânico dissolvido (solução do solo) & $0-5$ & $-0,386$ & $-0,245$ \\
Condutividade elétrica da solução do solo & $5-20$ & $-0,753$ & $-0,210$ \\
Condutividade elétrica da solução do solo & $0-5$ & $-0,737$ & $-0,170$ \\
K da solução do solo & $5-20$ & $-0,828$ & $-0,382$ \\
K da solução do solo & $0-5$ & $-0,647$ & $-0,174$ \\
Na da solução do solo & $5-20$ & $-0,537$ & $-0,170$ \\
Na da solução do solo & $0-5$ & $-0,745$ & $-0,297$ \\
\hline
\end{tabular}

ambientes perturbados (Barbosa \& Fernandes, 2003; Michereff Filho et al., 2004). Esse elevado nível de especialização ecológica também foi verificado em outros estudos com insetos (Kremen, 1992; Roth \& Perfecto, 1994).

Os dois primeiros eixos da ACC produziram baixa percentagem da variância da distribuição das espécies (eixo $1=30,4 \%$, eixo $=16,2$ ), indicando que existem outros aspectos a serem considerados nessa distribuição. Assim, a elevada correlação de espécies de formiga com variáveis de solo nos dois eixos $(=1,00)$ e a correlação significativa entre a frequência de ocorrência das espécies e as variáveis ambientais do teste de Monte Carlo ( $p<0,05$ para os dois eixos) devem ser examinadas com cautela. Outras variáveis ambientais não quantificadas, como aspectos 
associados ao microclima, à disponibilidade de alimentos e à estrutura da vegetação e da florística (Hölldobler \& Wilson, 1990; Lobry de Bruyn, 1999), seriam importantes para explicar a distribuição das espécies de formiga nas diferentes situações de uso da terra.

É reveladora a posição dos sítios sob mata à esquerda do primeiro eixo da ACC (Figura 5a), ficando as elipses dos demais sítios (CC, CB e CG) agrupadas à direita do diagrama. Das 17 variáveis de solo usadas na $\mathrm{ACC}$, apenas quatro delas ( $\mathrm{Al}$ de $0-5 \mathrm{~cm}$ e $\mathrm{CO}, \mathrm{Al} \mathrm{e}$ CTC de 5-20 cm de profundidade) mostraram maiores correlações com o segundo eixo da ACC, tornando as diferenças desse eixo pouco relevantes (Quadro 5). Sobressaem no primeiro eixo os atributos de resíduos orgânicos ( $\phi>2-4 \mathrm{~mm}$ e $\phi>4 \mathrm{~mm})$ e, de forma geral, os da solução do solo. Esse isolamento dos sítios de mata em relação aos alterados também é visualizado pelo diagrama de Cluster (Figura 6), mostrando que a similaridade na distribuição das espécies de formiga pelos sítios de mata sobrepõe-se ao efeito da área de localização do sítio.

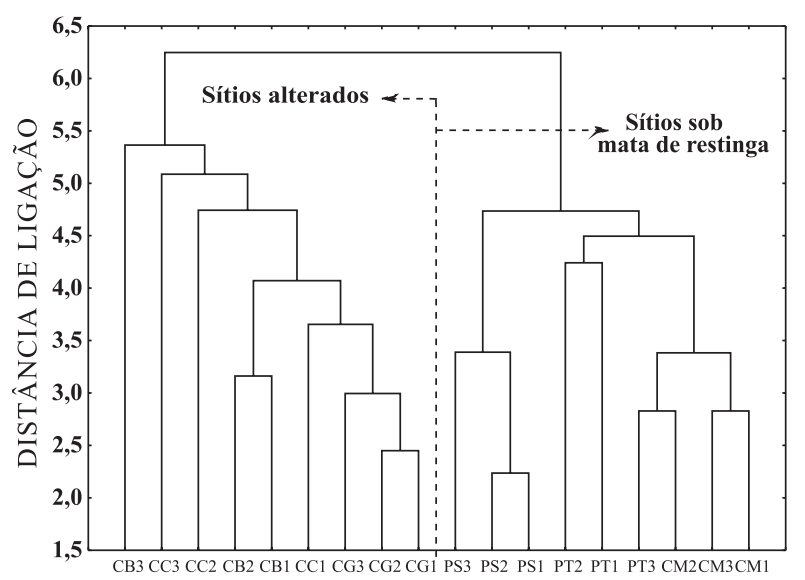

Figura 6. Diagrama de Cluster de 18 sítios de restinga (seis grupos de área e uso da terra com três repetições) a partir da frequência de ocorrência de espécies de formigas (71) amostradas nesses sítios. A figura aponta o isolamento dos sítios de mata relativamente aos sítios alterados. Áreas CM: Caju, mata; CG: Caju, capim-gengibre; CB: Caju, coqueiral do banco de germoplasma; CC: Caju, capoeira; PT: Pirambu, mata de topo; e PS: Pirambu, mata de sopé.

\section{CONCLUSÕES}

1. A distribuição de espécies nas comunidades de formigas amostradas apresentou elevado nível de especialização ecológica, com maior efeito do tipo de cobertura vegetal, e isolou os sítios sob mata das demais coberturas vegetais, conforme análises de correspondência canônica e de Cluster.
2. Independentemente da área (Caju ou Pirambu), as variáveis dos compartimentos orgânicos são aquelas que mais aproximam os sítios sob mata entre si e isolam estes do comportamento dos sítios alterados do Caju, apesar dos baixos valores de C orgânico do solo nos sítios da mata de sopé de nível intermediário de duna em Pirambu.

3. O sítios de mata de Pirambu (do topo e do sopé de duna) apresentaram várias características químicas da solução do solo diferenciadas de todos os sítios do Caju, independentemente da cobertura vegetal, ressaltando os teores médios mais elevados de condutividade elétrica, $\mathrm{Na}, \mathrm{K}$ e $\mathrm{Mg}$ nos sítios de Pirambu.

\section{LITERATURA CITADA}

AGOSTI, D.; MAJER, J.D.; ALONSO, L.E. \& SCHULTZ, T.R. Ants, standard methods for measuring and monitoring biodiversity. Washington, Smithsonian Institution Press, 2000. 280p.

BANDICK, A.K. \& DICK, R.P. Field management effects on soil enzyme activities. Soil Biol. Biochem., 31:1471-1479, 1999.

BARBOSA, L.P. \& FERNANDES W.D. Bait removal by ants (Hymenoptera: Formicidae) in managed and unmanaged Eucalyptus urophylla S.T. Blake Fields. Braz. J. Ecol., 8:61-63, 2003.

BOLTON, B. Synopsis and classification of Formicidae. Gainesville, American Entomological Institute, 2003. 370p.

BONNET, A. \& LOPES, B.C. Formigas de dunas e restingas da praia da Joaquina, Ilha de Santa Catarina, SC (Insecta: Hymenoptera). Biotemas, 6:107-114, 1993.

BOSCHETTI, A.N.G.; QUINTERO, C.E. \& BENAVIDEZ Q., R.A. Caracterização do fator capacidade de fósforo em solos de Entre Rios, Argentina. R. Bras. Ci. Solo, 22:9599, 1998.

BRASIL. Ministério das Minas e Energia. Secretaria Geral. Folhas SC.24/25 Aracaju/Recife; geologia, geomorfologia, pedologia, vegetação e uso potencial da terra. Rio de Janeiro, Projeto RADAMBRASIL, 1983. $856 \mathrm{p}$. (Levantamento de Recursos Naturais, 30)

CERQUEIRA, R. Biogeografia das restingas. In: ESTEVES F.A. \& LACERDA L.D., eds. Ecologia de restingas e lagoas costeiras. Macaé, Núcleo de Pesquisas Ecológicas de Macaé (NUPEM/UFRJ), 2000. p.65-75.

CINTRA, F.L.D.; LEAL, M.L.S. \& PASSOS, E.E.M. Root system distribution in dwarf coconuts. Oléagineux, 47:225-234, 1992.

DELABIE, J.H.C.; AGOSTI, D. \& NASCIMENTO, I.C. Litter ant communities of the Brazilian atlantic rain forest region. In: AGOSTI, D.; MAJER, J.D.; ALONSO, L. \& SCHULTZ, T., eds. Sampling ground-dwelling ants: Case studies from de world's rain forests. Perth, Curtin University, School of Environmental Biology, 2000. p.117 (Bulletin, 18) 
DELLA LUCIA, T.M.C.; LOUREIRO, M.C.; CHANDLER, L.; FREIRE, J.A.H.; GALVÃO, J.D. \& FERNANDES, B. Ordenação de comunidades de Formicidae em quatro agroecossistemas de Viçosa, Minas Gerais. Experientiae, 28:67-94, 1982

EMPRESA BRASILEIRA DE PESQUISA AGROPECUÁRIA EMBRAPA. Centro Nacional de Pesquisa de Solos. Manual de métodos de análise de solo. 2.ed. Rio de Janeiro, Embrapa Solos, 1997. 212p. (Documentos, 1)

EMPRESA BRASILEIRA DE PESQUISA AGROPECUÁRIA EMBRAPA. Centro Nacional de Pesquisa de Solos. Sistema brasileiro de classificação de solos. 2.ed. Rio de Janeiro, Embrapa Solos, 2006. 306p.

FELLER, C. \& BEARE, M.H. Physical control of soil organic matter dynamics in the tropics. Geoderma, 79:69-116, 1997.

GOMES, J.B.V.; RESENDE, M.; REZENDE, S.B. \& MENDONÇA, E.S. Solos de três áreas de restinga: I. Morfologia, caracterização e classificação. Pesq. Agropec. Bras., 33:1907-1919, 1998.

GOMES, J.B.V.; ARAÚJO F., J.C.; SIQUEIRA, O.J.W.; CARVALHO F., A. \& SOBRAL, L.F. Principais classes de solo do Estado de Sergipe. In: SOBRAL, L.F.; VIEGAS, P.R.A.; SIQUEIRA, O.J.W.; ANJOS, J.L.; BARRETTO, M.C.V. \& GOMES, J.B.V. Recomendações para o uso de corretivos e fertilizantes no Estado de Sergipe. Aracaju, Embrapa Tabuleiros Costeiros, 2007. p.25-48.

HAYNES, R.J. \& TREGURTHA, R. Effects of increasing periods under intensive arable vegetable production on biological, chemical and physical indices of soil quality. Biol. Fert. Soils, 28:259-266, 1999.

HÖLLDOBLER, B. \& WILSON, E.O. The ants. Cambridge, Belknap Press, 1990. 732p.

KREMEN, C. Assessing the indicator properties of species assemblages for natural areas monitoring. Ecol. Appl., $2: 203-217,1992$

LOBRY DE BRUYN, L.A. Ants as bioindicators of soil function in rural environments. Agric. Ecosys. Environ., 74:425441, 1999.

LUGO, A.E. \& BROWN, S. Management of tropical soils as sinks or sources of atmospheric carbon. Plant Soil, 149:27 41, 1993.

MANLAY, R.J.; CADET, P.; THIOULOUSE, J. \& CHOTTE, J. Relationships between abiotic and biotic soil properties during fallow periods in the sudanian zone of Senegal. Appl. Soil Ecol., 14:89-101, 2000.

McCUNE, B. \& MEFFORD, M.J. PC-ORD. Multivariate analysis of ecological data, Version 4. Oregon, MjM Software Design, 1999. 237p.

McLAUGHLIN, J.W.; LIU, G.; JURGENSEN, M.F. \& GALE, M.R. Organic carbon characteristics in a spruce swamp five years after harvesting. Soil Sci. Soc. Am. J., 60:12281236,1996

MICHEREFF FILHO, M.; GUEDES, R.N.C.; DELLA-LUCIA, T.M.C.; MICHEREFF, M.F.F. \& CRUZ, I. Non-target impact of chlorpyrifos on soil arthropods associated with no-tillage cornfields in Brazil. Int.J. Pest Manag., 50:9199, 2004.
MING, Y. \& RUSSEL, L.M. Predicted hygroscopic growth of sea aerosol. J. Geophys. Res., 106:28.259-28.274, 2001.

MOORE, T.R. Dynamics of dissolved organic carbon in forested and disturbed catchments, Westland, New Zealand 1. Maimai. Water Res. Res., 25:1321-1330, 1989.

NSABIMANA, D.; HAYNES, R.J. \& WALLIS, F.M. Size, activity and catabolic diversity of the soil microbial biomass as affected by land use. Appl. Soil Ecol., 26:81-92, 2004.

PÉREZ, D.V. Avaliação de parâmetros críticos para especiação de $\mathrm{Al}, \mathrm{Fe}$ e $\mathrm{Mn}$ em solução de solos sob diferentes sistemas de uso e manejo. Rio de Janeiro, PUC, 2002. 193p. (Tese de Doutorado)

RHOADES, J.D. Soluble salts. In: PAGE, A.L., ed. Methods of soil analysis. 2.ed. Madison, ASA/SSSA, 1982. v.1. p.167179 (Agronomy Monograph, 9)

ROTH, D.S. \& PERFECTO, I. The effects of management systems on ground-foraging ant diversity in Costa Rica. Ecol. Appl., 4:423-436, 1994.

SCHNURER, J. \& ROSSWALL, T. Fluorescein diacetate hydrolysis as a measure of total microbial activity in soil and litter. Appl. Environ. Microbiol., 43:1256-1261, 1982.

SICARDI, M.; GARCÍA-PRÉCHAC, F. \& FRIONI, L. Soil microbial indicators sensitive to land use conversion from pastures to commercial Eucalyptus grandis (Hill ex Maiden) plantations in Uruguay. Appl. Soil Ecol., 27:125133,2004

STATISTICA (data analysis software system), version 7 . www.statsoft.com. StatSoft, Inc., 2004.

SUGUIO, K. Dicionário de geologia sedimentar e áreas afins. Rio de Janeiro, Bertrand Brasil, 1998. 1222p.

TER BRAAK, C.J.F. Ordination. In: JONGMAN, R.H.G.; TER BRAAK, C.J.F.; van TOGEREN, O.F.R., eds. Data analysis in community and landscape ecology. Cambridge, Cambridge University Press, 1995. p.91-173.

UDAWATTA, R.P.; KREMER, R.J.; ADAMSON, B.W. \& ANDERSON, S.H. Variations in soil aggregate stability and enzyme activities in a temperate agroforestry practice. Appl. Soil Ecol., 39:153-160, 2008.

VARGAS, A.B.; MAYHÉ-NUNES, A.J.; QUEIROZ, J.M.; SOUZA, G.O. \& RAMOS, E.F. Efeitos de fatores ambientais sobre a mirmecofauna em comunidade de restinga no Rio de Janeiro, RJ. Neotrop. Entomol., 36:2837, 2007.

WHIPIKEY, C.E.; CAPO, R.C.; CHADWICK, O.A. \& STEWART, B.W. The importance of sea spray to the cation budget of a coastal Hawaiian soil: A strontium isotope approach. Chem. Geol., 168:37-48, 2000.

WILSON, E.O. Which are the most prevalent ant genera? Studia Entomol., 19:187-200, 1976.

WIRTH, R.; HERZ, H.; RYEL, R.J.; BEYSCHLAG, W. \& HÖLLDOBLER, B. Herbivory of leaf-cutting ants: A case study on Atta colombica in the tropical rainforest of Panama. New York, Springer, 2003. 230p. (Ecological Studies, 164) 